\title{
Preventive effects of crocin on neuronal damages induced by D-galactose through AGEs and oxidative stress in human neuroblastoma cells (SH-SY5Y)
}

\author{
Somaye Heidari', Soghra Mehri ${ }^{2,1}$, Vahidesadat Shariaty², Hossein Hosseinzadeh*1 \\ 1 Department of Pharmacodynamics and Toxicology ,School of Pharmacy, Mashhad University of Medical Sciences, Mashhad, I. R. Iran \\ ${ }^{2}$ Pharmaceutical Research Center, Pharmaceutical Technology Institute, Mashhad University of Medical Sciences, Mashhad, Iran
}

\section{Key Words}

D-galactose, Crocin, Saffron, Aging, Reactive oxygen species, Advanced glycation end products

\section{Abstract \\ Objective: D-galactose (D-gal) is well-known agent to induce aging process. In the present study, we se- lected crocin, the main constituent of Crocus sativus L. (saffron), against D-gal- induced cytotoxicity in human neuroblastoma SH-SY5Y cells.}

Methods: Pretreated cells with crocin (25-500 $\mu \mathrm{M}, 24$ h) were exposed to D-gal (25-400 mM, $48 \mathrm{~h})$. The MTT assay was used for determination cell viability. Dichlorofluorescin diacetate assay (DCF-DA) and senescence associated $\beta$-galactosidase staining assay (SA- $\beta$-gal) were used to evaluate the generation of reactive oxygen species and beta-galactosidase as an aging marker, respectively. Also advanced glycation end products (AGEs) expression which is known as the main mechanism of age-related diseases was measured by western blot analysis.

Results: The findings of our study showed that treatment of cells with D-gal (25-400 mM) for 48h decreased cell viability concentration dependency. Reactive ox-

Received: Jul 02, 2017 Reviewed: Feb 18, 2018 Accepted: Feb 26, 2018 ygen species (ROS) levels which are known as main factors in age-related diseases increased from $100 \pm$ $8 \%$ in control group to $132 \pm 22 \%$ in D-gal ( $200 \mathrm{mM})$ treated cells for $48 \mathrm{~h}$. The cytotoxic effects of D-gal decreased with $24 \mathrm{~h}$ crocin pretreatment of cells. The cell viability at concentrations of $100 \mu \mathrm{M}, 200 \mu \mathrm{M}$ and 500 $\mu \mathrm{M}$ increased and ROS production decreased at concentrations of 200 and $500 \mu \mathrm{M}$ to $111.5 \pm 6 \%$ and 108 $\pm 5 \%$, respectively. Also lysosomal biomarker of aging and carboxymethyl lysine (CML) expression as an AGE protein, significantly increased in D-gal $200 \mathrm{mM}$ group after $48 \mathrm{~h}$ incubation compare to control group. Pretreatment of SHSY-5Y cells with crocin $(500 \mu \mathrm{M})$ before adding D-gal significantly reduced aging marker and CML formation.

Conclusion: Treatment of SH-SY5Y cells with crocin before adding of D-gal restored aging effects of D-gal concentration dependency. These findings indicate that crocin has potent anti- aging effects through inhibition of AGEs and ROS production.

\section{Introduction}

Aging is a progressive and irreversible phenomenon with cell and organ damages that enhances aging diseases such as Alzheimer. About $40 \%$ of over 60 years old suffer from varying degrees of cognitive dysfunctions and movement disorders [1].

The production of free radicals and advanced glyca- 
tion end products (AGEs) are the main mechanisms of aging pathogenesis through development of protein damages. The non-enzymatic reaction between reducing sugars and amino groups of proteins is called glycation or Miallard reaction producing Schiff bases which switch to Amadori products. AGEs that are generated from oxidation of unstable Amadori products and its irreversible crosslinked to tissues increase free radicals production rate 50 times more than unglycated molecules [2]. The most reported AGEs in the studies are $\mathrm{N} \varepsilon$-(carboxymethyl)lysine (CML), Ne -(carboxyethyl)lysine (CEL), hydroimidazolones (HIs), pentosidine and pyrraline. CML, the abundant AGE in the heated foods, is most selected as an AGE molecule in laboratory investigations [3]. AGEs accumulation in tissue and elevated levels of ROS can induce molecular (DNA, protein and phospholipids) damages and disturb cellular function [4].

D-galactose (D-gal) is a simple sugar that is found in some foods and can be made by the body. Generally, it is metabolized completely in normal level by D-galactokinase and galactose-1- phosphate uridyltransferase. However, an elevation level of D-gal induces oxidative stress and excessive D-gal. D-gal is oxidized into aldehydes and hydrogen peroxide and also it causes galactitol accumulation in cells which reacts with amines of amino acids in proteins to form glycation products [5]. Therefore, D-gal increases ROS production. Oxidative stress is one of the main mechanism of neurodegeneration that leads to other disorder such as stroke, multi-infarct dementia, Alzheimer's, Parkinson's and Huntington's disease [6, 7]. Regarding to important role of oxidative stress in aging phenomena, it seems that, this process can be postponed with exogenous antioxidants consumption. [8]. There are several evidences that plants as natural anti- oxidants can improve brain aging and cognitive dysfunction [9].

Saffron is the colored stigma of the plant Crocus sativus L. from Iridaceae family [10]. It is recently used for flavoring and coloring food and in traditional medicine has been used as anodyne, tranquilizer, antidepressant and stomachic [11]. The main active constituents of saffron are picrocrocin (bitter principles), safranal (volatile agents), crocetin and its glycoside crocin (dye materials) [12]. The major effects of saffron extracts and its active constituents are neuroprotective [13], antioxidant [14], anti-cancer [15], anti-diabetic and anti-hyperlipidemic[16], anti-atherosclerotic [17], anti-arthritic [18], and memory enhancement effects [19]. Crocin is a carotenoid pigment which has several health-promoting effects [20]. In a recent study, crocin attenuated acrolein induced tau hyper phosphorylation and malondialdehyde formation in the rat cerebral cortex by modulation mitogen-activated protein kinases (MAPKs) signaling pathway and elevation of glutathione levels [21]. Also, in streptozotocin induced-diabetic rats, administration of crocin exhibited hypoglycemic effects and decreased the level of AGEs formation[22].

Since, the protective effect of crocin against brain aging through D-gal and AGE production has not been studied, so in the present study we used human neuronal cells ( $\mathrm{SH}-$ SY5Y) to investigate aging mechanisms and protective effects of crocin on oxidative stress and AGEs formation caused by high level of D-gal.

\section{Materials and Methods}

D-gal (99\% purity) and fuorescent probe 2,7-dichlorofluorescein diacetate (DCF-DA) were purchased from Sigma. Senescence beta-galactosidase staining Kit (\#9860) was purchased from cell signaling and rabbit polyclonal CML was obtained from Abcam. Polyvinylidene fluoride (PVDF) membrane was provided from Bio-Rad.

Crocin crystals were obtained from saffron stigmas (purchased from Novin Saffron of Ghaen, Khorasan province, Northeast of Iran) by using crystallization method as previously has been described [23].

The SH-SY5Y human neuroblastoma cell line was obtained from Pasteur institute (Tehran, Iran). Cells were cultured in Dulbecco's modified Eagle's medium and Ham's F-12 Nutrient mixture (DMEM-F12) supplemented with $15 \%(\mathrm{v} / \mathrm{v})$ fetal bovine serum, $100 \mathrm{U} / \mathrm{ml}$ penicillin, and $100 \mathrm{mg} / \mathrm{ml}$ streptomycin and maintained at 37 ${ }^{\circ} \mathrm{C}$ with 95\% humidified air and 5\% CO2. Cells in culture flasks were harvested for experiments at $80 \%$ confluence. Cell viability was determined by using the MTT (3-[4,5-dimethylthiazol-2-yl]-2,5- diphenyltetrazolium bromide) reduction assay that has been described previously [24]. Cells were incubated in 96-well plates with 5000 cell in each well. Different crocin concentrations (25- $500 \mu \mathrm{M})$ were added to SH-SY5Y cells incubated in a plate for 72 $h$ to investigate crocin effects on cell viability. In the separate plates, the cells were incubated with different concentrations of D-gal (25-400 mM) for $24 \mathrm{~h}$ and $48 \mathrm{~h}$ to find appropriate treatment period and D-gal concentration. Finally, D-gal at concentration of $200 \mathrm{mM}$ selected and the cells after $24 \mathrm{~h}$ pretreatment with crocin $(25-500 \mu \mathrm{M})$ were incubated with $200 \mathrm{mM}$ D-gal for $48 \mathrm{~h}$ to investigate the protective effects of crocin on D-gal neurotoxicity. After ending each treatment, cells were incubated with MTT solution (final concentration $0.5 \mathrm{mg} / \mathrm{mL}$ ) for $2 \mathrm{~h}$ at $37^{\circ} \mathrm{c}$. Then, the medium was removed and the purple formazan crystals were dissolved in $150 \mu \mathrm{l}$ dimethylsulfoxide (DMSO). Absorbance was measured at $545 \mathrm{~nm}(630 \mathrm{~nm}$ as a reference) in an ELISA reader (Start Fax- 2100, UK). The dichlorofluorescin diacetate assay was used to evaluate the generation of reactive oxygen species [25]. H2DCF-DA readily crosses through the cell membrane and is enzymatically hydrolyzed by intracellular esterases to nonfluorescent H2DCF, which is oxidized in the presence of ROS to highly fluorescent DCF (2',7'-dichlorofluorescin). The DCF fluorescence intensity is equal to the amount of intracellular ROS. In brief, the SH-SY5Y cells were exposed to crocin $(25-500 \mu \mathrm{M})$ in a 96 well culture plate for $24 \mathrm{~h}$, then $200 \mathrm{mM}$ D-gal was added to each well and the exposure time was $48 \mathrm{~h}$. After washing of the cells with PBS solution, the cells were incubated with $20 \mu \mathrm{M}$ DCF-DA for $30 \mathrm{~min}$ at $37 \mathrm{oC}$ in the dark. Bio Tek Synergy $\mathrm{H} 4$ plate reader at excitation and emission wavelengths of $488 \mathrm{~nm}$ and $527 \mathrm{~nm}$, respectively measured intensity fluorescence of oxidized dichlorofluorescin.

Senescence associated $\beta$-galactosidase activity assay has been defined at $\mathrm{pH}$ : 6.0 to investigate expression of lysosomal $\beta$-galactosidase protein as a most widely used biomarker for senescent cells [26]. The test was performed according to the manufacturer's protocol of commercial 
senescence-associated $\beta$-galactosidase kit (cell signaling\#9860). Briefly, cells were seeded at $80^{*} 10 \mathrm{cell} / \mathrm{well}$ in a six-well plate with or without $500 \mu \mathrm{M}$ crocin pretreatment for $24 \mathrm{~h}$ followed by treatment with D-gal $(200 \mathrm{mM})$ for 48 h. Cells were washed with PBS and incubated with SA- $\beta$ gal detection solution at $37^{\circ} \mathrm{C}$ for at least $12 \mathrm{~h}$. After washing with PBS, cells were observed under light microscopy (Jenus, China) and positive staining cells were counted in 10 random fields of each well.

Cells were harvested and lysed in lysis buffer containing 50 mM Tris-HCl (pH: 7.4), 2 mM EDTA, 2 mM EGTA, 10 $\mathrm{mM} \mathrm{NaF}, 1 \mathrm{mM}$ sodium orthovanadate (Na3VO4), $10 \mathrm{mM}$ $\beta$ glycerophosphate, $0.2 \% \mathrm{~W} / \mathrm{V}$ sodium deoxycholate, 1 mM phenylmethylsulfonyl fluoride (PMSF), and complete protease inhibitor cocktail, then western blotting was performed as previously described [24, 27]. The total proteins were electrophoresed in 15\% SDS-PAGE gels, transferred to polyvinylidene fluoride (PVDF) membranes. Then, the blots were blocked with $2 \%$ skim milk for $1 \mathrm{~h}$ at room temperature. After blocking, membranes were incubated with the primary antibodies at 1000-fold dilutions: anti-CML (ab27684) for overnight at 4o C and anti- GAPDH (\#ab8245) for $2 \mathrm{~h}$ at room temperature. After that the membranes were washed three times with $0.1 \%$ Tween 20 and TBST then incubated with Horseradish-peroxidase conjugated anti-rabbit antibody (\#7074 Cell Signaling) at 1:3000 dilutions $90 \mathrm{~min}$ at room temperature. At the end of process protein bands were detected by enhanced chemiluminescence (ECL) reagent and Alliance $4.7 \mathrm{Gel}-$ doc (UK). Protein bands analyzing were performed using UVtec software (UK).

All data were expressed as means \pm SD and analyzed using analysis of variance (ANOVA) followed by the TukeyKramer post-hoc test for multiple comparisons. Differences were considered statistically significant when $\mathrm{P}<0.05$.

\section{Results}

Exposure of SH-SY5Y cells to different concentrations of D-gal $(25-400 \mathrm{mM})$ for 24 and $48 \mathrm{~h}$, concentration-dependently decreased cell viability. Significant reduction in cell viability was observed following $48 \mathrm{~h}$ exposure (fig $1 \mathrm{~A})$. As shown in fig $1 \mathrm{~B}$, pretreatment of cells with crocin $(25-500 \mu \mathrm{M}), 24 \mathrm{~h}$ before exposure to D-gal $(200 \mathrm{mM})$ significantly attenuated the effects of D-gal at $100 \mu \mathrm{M}$ $(\mathrm{p}<0.05), 200 \mu \mathrm{M}(\mathrm{p}<0.05)$ and $500 \mu \mathrm{M}(\mathrm{p}<0.01)$ as compared to D-gal- treated cells. Also, treatment of cells with different crocin concentrations (25- 500 $\mu \mathrm{M})$ alone for 72 $\mathrm{h}$ did not affect cell proliferation (fig 1C).

Treatment of cells with D-gal ( $200 \mathrm{mM})$, for $48 \mathrm{~h}$ elevated intracellular ROS production up to $132 \pm 22 \%$ in SH-SY5Y cells $(\mathrm{p}<0.001$ vs control). This effect was reduced through incubation of cells with crocin $24 \mathrm{~h}$ before adding D-gal. A significant reduction in ROS production was observed in 200 and $500 \mu \mathrm{M}$ of crocin concentrations $(\mathrm{p}<0.05), 111.5 \pm$ $6 \%$ and $108 \pm 5 \%$, respectively ( $<<0.05$ ) (fig 2 ).

$\beta$-gal staining assay was performed according to above statement and the SH-SY5Y cells treated with D-gal 200 $\mathrm{mM}$ showed more positive blue staining cells when compared to control group. Pretreatment of cells with crocin $(500 \mu \mathrm{M})$ induced significant reduction in senescence marker $(\mathrm{p}<0.05)($ fig $3 \mathrm{~A})$. The percentage of senescence cells showed in fig $3 \mathrm{~B}$ was $11.9 \pm 1.18 \%(\mathrm{p}<0.05)$ in $\mathrm{D}$-gal incubated cells versus control group $(6.4 \% \pm 0.43)$. Crocin pretreated cells had $5.94 \pm 0.84 \%$ cellular aging marker which was significantly less than D-gal group $(\mathrm{p}<0.05)$. As shown in fig 4, neuronal cells exposure to D-gal (200 $\mathrm{mM}$ ) for $48 \mathrm{~h}$, significantly increased CML formation to $139.5 \pm 14 \%$ ( $<<0.01$ vs control group), whereas pretreatment of cells with crocin $(500 \mu \mathrm{M})$ for $24 \mathrm{~h}$ reduced CML generation to $107.6 \pm 14 \%$ ( $\mathrm{p}<0.05$ vs $\mathrm{D}$-gal group).

\section{Discussion}

In this study, the anti-aging effects of crocin were evaluated in a reliable aging model induced by D-gal. Critical aging changes have been formed with D-gal in several in vitro and in vivo models $[5,28]$. According to our results, D-gal not only increased cell death and intracellular ROS production but also induced cellular senescence and CML formation in SH-SY5Y cells. Pretreatment with crocin markedly suppressed cellular aging in SH-SY5Y cells through free radical scavenging activity. In support of these findings, previous results have shown that crocin has potent antioxidant and neuroprotective effects [29, 30].

SA- $\beta$-gal activity at $\mathrm{pH}=6$ has been clearly elevated in different aged cells and tissues of old animals [31]. According to other research projects, in our study, SH-SY5Y cells which treated by D-gal $200 \mathrm{mM}$ for $48 \mathrm{~h}$ showed more $\beta$-gal senescence staining cells when compared to control group [5]. Betagalactosidase aging marker in the pretreated cells with crocin, significantly decreased in comparison to D-gal group.

In the different aging models, increased amounts of other cellular senescence markers such as ROS level and oxidative DNA damage have been observed [32]. Oxidative stress plays a crucial role in aging and ROS levels increase in the senescence cells with numerous mechanisms [33]. Crocin was shown obvious antioxidant effects in the different oxidative conditions. Ischemia- reperfusion-induced oxidative stress in kidney and skeletal muscle were reduced following pretreatment with crocin $[34,35]$.

Saffron and its carotenoid crocin reduced diabetic neuropathy in PC12 cells induced by high level of glucose through inhibition of ROS production [36].

Crocin administration, diminished ROS production, increased GSH content andSOD activity in rat retina after ischemia- reperfusion injury [37]. In our study, incubation of SHSY-5Y cells with D-gal $200 \mathrm{mM}$ for $48 \mathrm{~h}$ increased ROS production while pretreatment of cells with crocin ameliorated ROS formation in the dose-dependent manner. It has been shown that $\mathrm{D}$-gal increases lipid peroxidation and SOD activity while decreases catalase and glutathione peroxidase directly or via activation AGE/RAGE pathway [38]. Also, in the neurodegeneration disorders, the elevation of advanced glycation end products formation has been reported. AGEs molecules via AGE/RAGE pathway activate extracellular proteins such as $ß$-amyloid peptides and lead to oxidative stress and inflammatory responses [39]. Recently crocin has been shown antiglycating effect in diabetic and atherosclerotic rats [22]. Similarly, in our 
research, pretreatment with crocin $(500 \mu \mathrm{M})$ significantly decreased the most important advance glycation end product, CML, which increased in D-gal treated cells.

It seems that AGEs and ROS can stimulate the production of each other and both of them are the major mechanisms of brain aging. AGEs are produced from glucose and fructose under oxidative and antioxidative conditions. Also, AGE-modified proteins and free radicals lead to elevation of pro-inflammatory markers, including tumor necrosis factor $\alpha(\mathrm{TNF} \alpha), \mathrm{IL}-1 \beta$ and NF- $\mathrm{KB}$ [40]. The expression of pro-inflammatory cytokines in the cerebral cortex and hippocampus regions elevates in neurodegenerative disorders [41].

\section{Conclusion}

This study shows that crocin protects SHSY5Y cells against D-gal induced aging probably through the reduction of intracellular ROS and AGEs formation. Therefore, we should investigate molecular pathways affected by AGEs and ROS that contribute to brain aging mechanisms.

\section{Acknowledgments}

The authors are thankful to the Vice Chancellor of Research, Mashhad University of Medical Sciences for financial support. The results described in this paper are part of a Ph. D. thesis of Dr. Somaye Heidari.

\section{Conflict of interest}

All authors state that there are no actual or potential conflicts of interest. 
Figure 1A

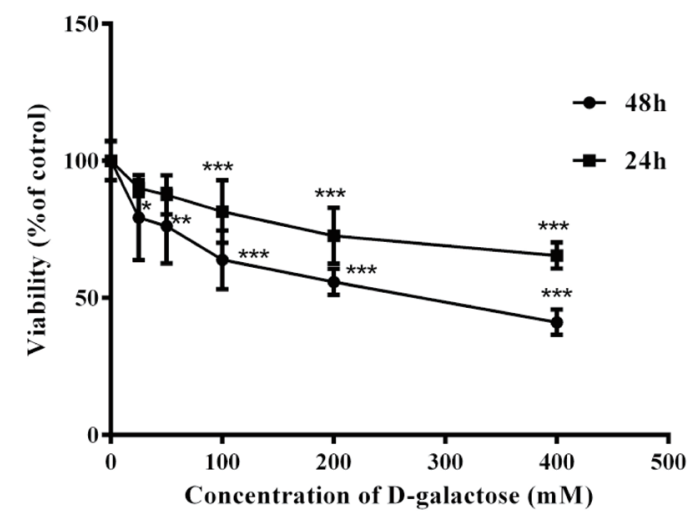

Figure 1C

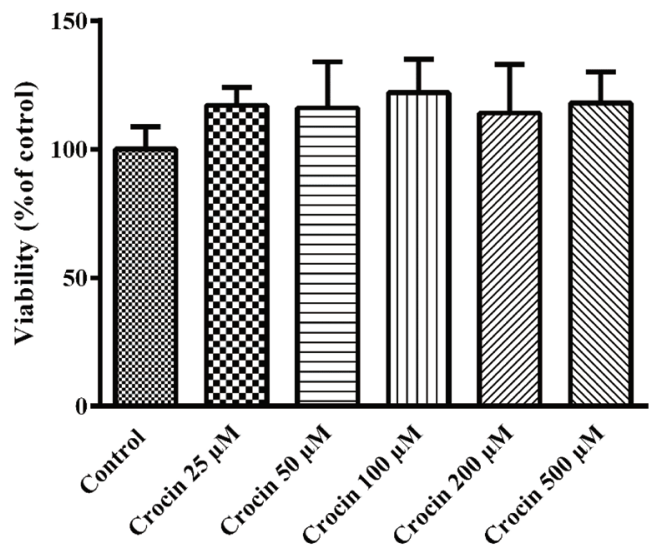

Figure 1B

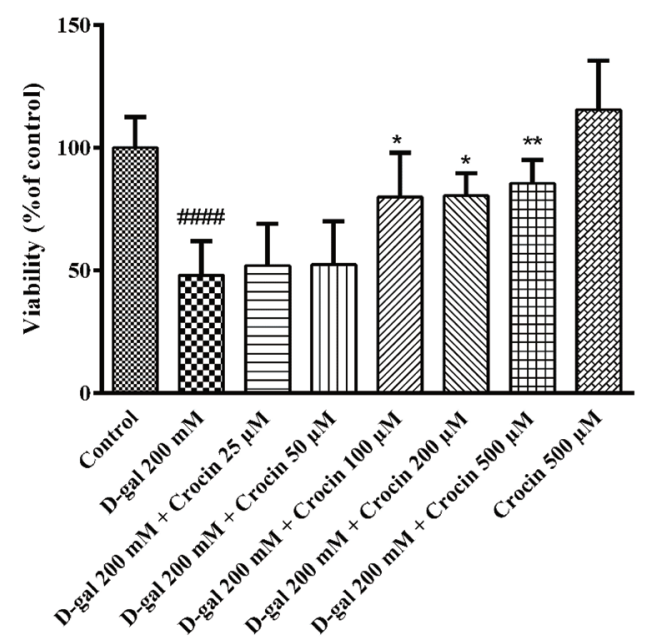

Figure 1 (A) Viability of SH-SY5Y cells incubated with 25-400 mM D-galactose for 24 and 48h. (B) Viability of SH-SY5Y cells incubated with $200 \mathrm{mM}$ D-galactose (DG) with or without $24 \mathrm{~h}$ pretreated crocin $(25-500 \mu \mathrm{M})$. (C) Viability of SH-SY5Y cells incubated with crocin $(25-500 \mu \mathrm{M})$ alone for $72 \mathrm{~h}$. Values are expressed as means $\pm \mathrm{SD}(\mathrm{n}=6)$. \# $\mathrm{P}<0.05$, \#\#p $<0.01$ and \#\#\#p $<0.001$ vs. control, ${ }^{*} \mathrm{p}<$ 0.05 and ${ }^{* *} \mathrm{p}<0.01 \mathrm{vs,D}$-gal at the same incubation time.

Figure 2

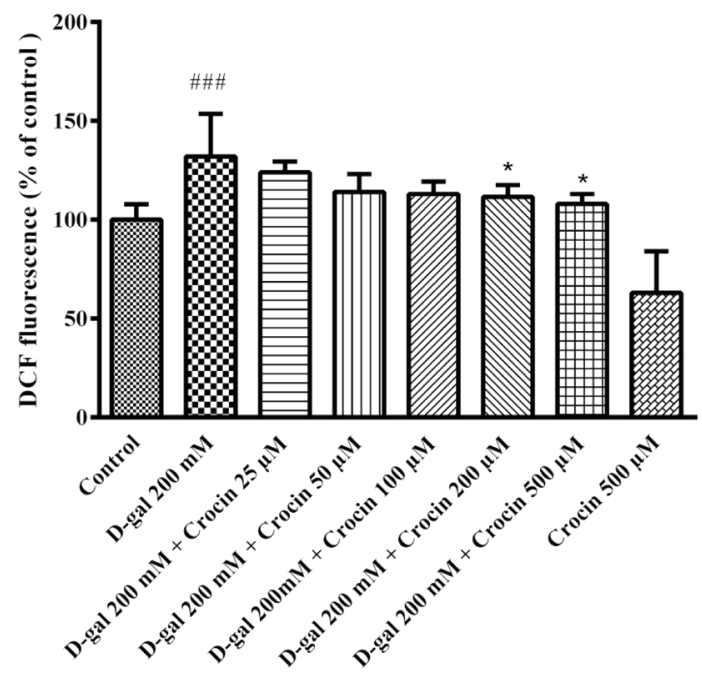

Figure 2 Effect of crocin on D-gal induced intracellular ROS formation in SH-SY5Y cells after 30 min incubation with $20 \mu \mathrm{M}$, 70 -dichlorofluorescin (DCF). Data are expressed as means \pm SD $(\mathrm{n}=6)$. \#\#\#P<0.05 vs. control, ${ }^{*} \mathrm{P}<0.05$ vs. D-gal treated cells at the same incubation time. 


\section{Figure 3B}
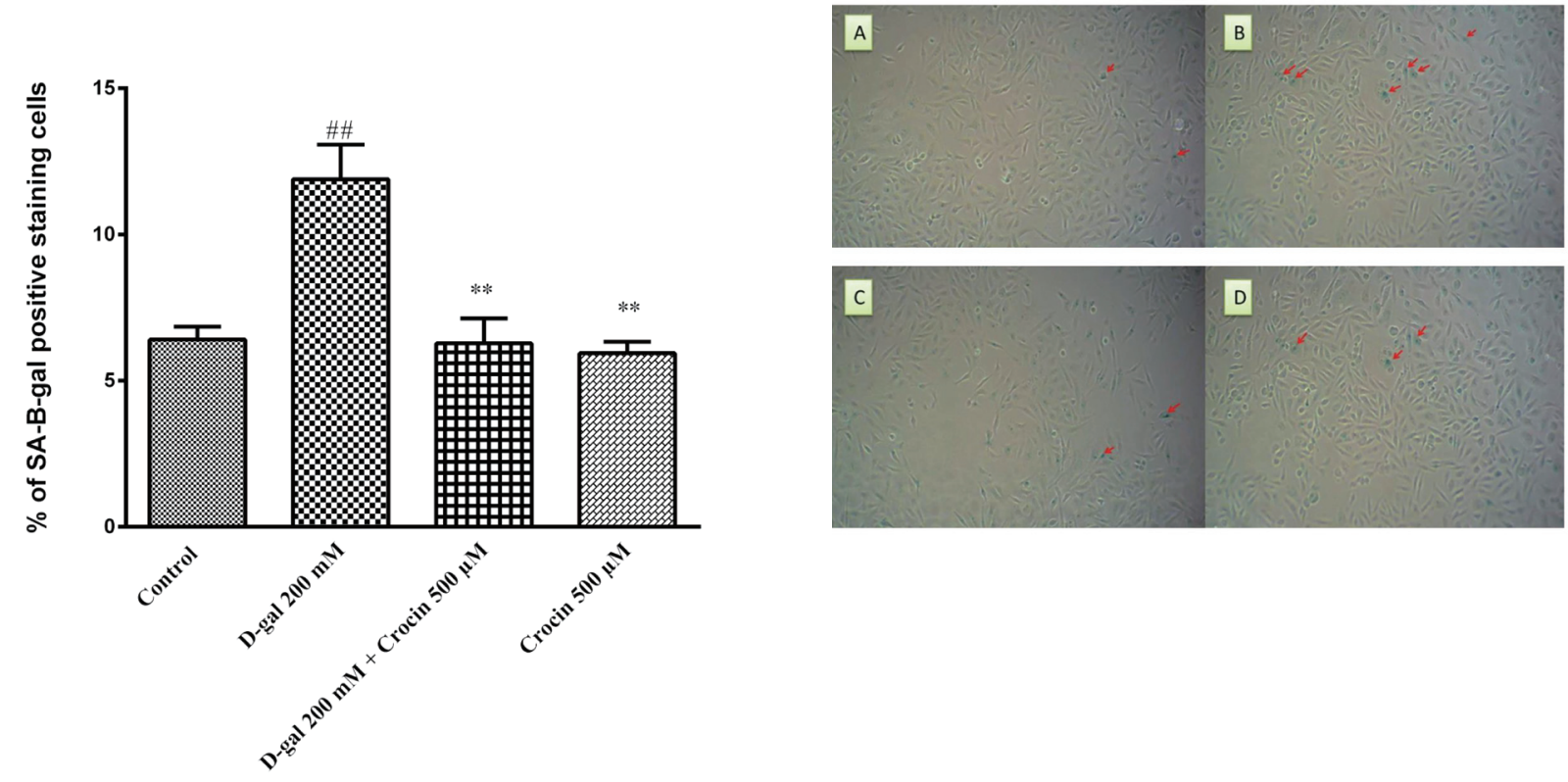

Figure 3 (A) Effect of crocin on D-gal induced cellular senescence in SH-SY5Y cells. Cells were treated with SA-b-gal for at least 12h. Arrows show staining senescent cells. (B) The percentage of SA-B-gal positive cells. Data are expressed as means \pm SD. \#\#p $<0.01$ vs. control, ${ }^{* *} \mathrm{p}<0.01$ vs. D-gal treated cells at the same incubation time. A, control group B, D-gal 200mM group C, D-gal $200 \mathrm{mM}+\mathrm{crocin}$ $500 \mu$ Mgroup D, crocin 500 $\mu \mathrm{M}$ group.

Figure 4A

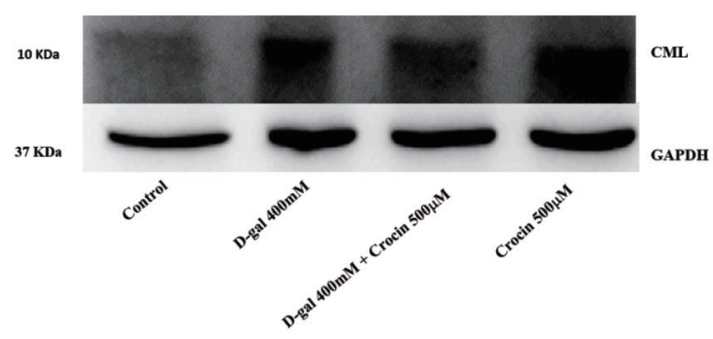

Figure 4B

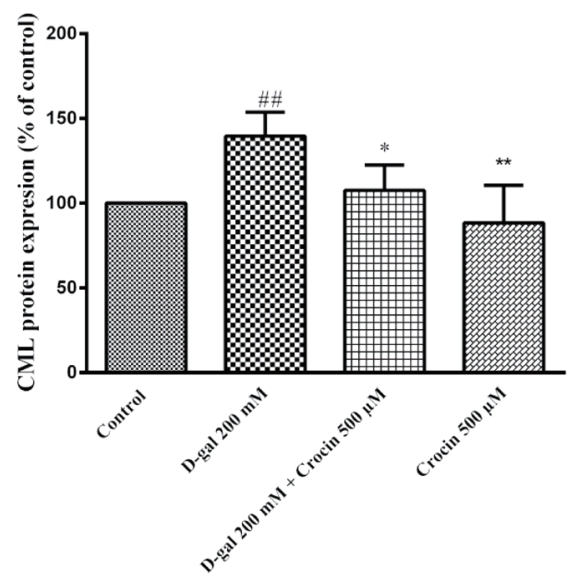

Figure 4 Expressions of $\mathrm{N}-\varepsilon$-(carboxylmethyl)lysine (CML) protein in SH-SY5Ycells treated of $200 \mathrm{mM}$ D-gal with or without crocin pretreatment $(500 \mu \mathrm{M})$ for $24 \mathrm{~h}$. (A) Western blots of CML protein (B) The quantitative protein levels of CML. Data are expressed as the mean \pm SD of four separate experiments. $\# \# \mathrm{P}<0.01$ vs. control, ${ }^{*} \mathrm{P}<0.05,{ }^{* *} \mathrm{p}<0.01 \mathrm{vs}$. D-gal treated cells. 


\section{References}

1. Fried LP, Ferrucci L, Darer J, Williamson JD, Anderson G. Untangling the concepts of disability, frailty, and comorbidity: implications for improved targeting and care. J Gerontol A Biol Sci Med Sci. 2004;59(3):255-63.

2. Nowotny K, Jung T, Hohn A, Weber D, Grune T. Advanced glycation end products and oxidative stress in type 2 diabetes mellitus. Biomolecules. 2015;5(1):194222.

3. Li L, Han L, Fu Q, Li Y, Liang Z, Su J, et al. Formation and inhibition of $\mathrm{N} \varepsilon$ - (carboxymethyl)lysine in saccharide-lysine model systems during microwave heating. Molecules. 2012;17(11):12758-70.

4. Xu LQ, Xie YL, Gui SH, Zhang X, Mo ZZ, Sun CY, et al. Polydatin attenuates d-galactose- induced liver and brain damage through its anti-oxidative, anti-inflammatory and anti-apoptotic effects in mice. Food Funct. 2016;7(11):4545-55.

5. Liu YY, Nagpure BV, Wong PT, Bian JS. Hydrogen sulfide protects SH-SY5Y neuronal cells against d-galactose induced cell injury by suppression of advanced glycation end products formation and oxidative stress. Neurochemistry int. 2013;62(5):603-9.

6. Hsieh HM, Wu WM, Hu ML. Soy isoflavones attenuate oxidative stress and improve parameters related to aging and Alzheimer's disease in C57BL/6J mice treated with D-galactose. Food Chem Toxicol. 2009;47(3):625632.

7. Hu LF, Lu M, Tiong CX, Dawe GS, Hu G, Bian JS. Neuroprotective effects of hydrogen sulfide on Parkinson's disease rat models. Aging cell. 2010;9(2):135-146.

8. Sadowska-Bartosz I, Bartosz G. Effect of antioxidants supplementation on aging and longevity. Biomed Res Int. 2014;2014:404680.

9. Head E. Oxidative damage and cognitive dysfunction: antioxidant treatments to promote healthy brain aging. Neurochem res. 2009;34(4):670-678.

10. Abdullaev FI. Biological effects of saffron. BioFactors (Oxford, England). 1993;4(2):83-6.

11. Bostan HB, Mehri S, Hosseinzadeh H. Toxicology effects of saffron and its constituents. Iran J Basic Med Sci. 2017;20(2):110-21.

12. Moshiri M, Vahabzadeh M, Hosseinzadeh H. Clinical applications of saffron (Crocus sativus) and its constituents: a review. Drug Res (Stuttq). 2015;65(6):287-295.

13. Vahdati Hassani F, Naseri V, Razavi BM, Mehri S, Abnous $\mathrm{K}$, Hosseinzadeh $\mathrm{H}$. Antidepressant effects of crocin and its effects on transcript and protein levels of CREB, BDNF, and VGF in rat hippocampus. Daru. 2014;22(1):16.

14. Ochiai T, Ohno S, Soeda S, Tanaka H, Shoyama Y, Shimeno $\mathrm{H}$. Crocin prevents the death of rat pheochromyctoma (PC-12) cells by its antioxidant effects stronger than those of alpha- tocopherol. Neurosci Lett. 2004;362(1):61-4.

15. Abdullaev FI, Espinosa-Aguirre JJ. Biomedical properties of saffron and its potential use in cancer therapy and chemoprevention trials. Cancer Detect Prev. 2004;28(6):426-32.
16. Samarghandian S, Azimi-Nezhad M, Samini F. Ameliorative effect of saffron aqueous extract on hyperglycemia, hyperlipidemia, and oxidative stress on diabetic encephalopathy in streptozotocin induced experimental diabetes mellitus. Biomed Res Int. 2014;2014:920857.

17. He SY, Qian ZY, Tang FT, Wen N, Xu GL, Sheng L. Effect of crocin on experimental atherosclerosis in quails and its mechanisms. Life Sci. 2005;77(8):907-921.

18. Ding Q, Zhong H, Qi Y, Cheng Y, Li W, Yan S, et al. Anti-arthritic effects of crocin in interleukin-1beta-treated articular chondrocytes and cartilage in a rabbit osteoarthritic model. Inflamm res. 2013;62(1):17-25.

19. Ghadrdoost B, Vafaei AA, Rashidy-Pour A, Hajisoltani R, Bandegi AR, Motamedi F, et al. Protective effects of saffron extract and its active constituent crocin against oxidative stress and spatial learning and memory deficits induced by chronic stress in rats. Eur J Pharmacol. 2011;667(1-3):222-9.

20. Alavizadeh SH, Hosseinzadeh H. Bioactivity assessment and toxicity of crocin: a comprehensive review. Food Chem Toxicol. 2014;64:65-80.

21. Rashedinia M, Lari P, Abnous K, Hosseinzadeh H. Protective effect of crocin on acrolein- induced tau phosphorylation in the rat brain. Acta Neurobiol Exp (Wars). 2015;75(2):208-19.

22. Shirali S, Zahra Bathaie S, Nakhjavani M. Effect of crocin on the insulin resistance and lipid profile of streptozotocin-induced diabetic rats. Phytother Res. 2013;27(7):1042-7.

23. Hadizadeh F, Mohajeri SA, Seifi M. Extraction and purification of crocin from saffron stigmas employing a simple and efficient crystallization method. Pak J Biol Sci. 2010;13(14): 691-8.

24. Liu YY, Bian JS. Hydrogen sulfide protects amyloid- $\beta$ induced cell toxicity in microglia. J Alzheimer Dis. 2010;22(4):1189-1200.

25. Li Y, Shi W, Li Y, Zhou Y, Hu X, Song C, et al. Neuroprotective effects of chlorogenic acid against apoptosis of PC12 cells induced by methylmercury. Environ Toxicol Pharmacol. 2008;26(1):13-21.

26. Lee BY, Han JA, Im JS, Morrone A, Johung K, Goodwin $\mathrm{EC}$, et al. Senescence-associated $\beta$-galactosidase is lysosomal $\beta$-galactosidase. Aging cell. 2006;5(2):187-195.

27. Liu YY, Sparatore A, Del Soldato P, Bian JS. ACS84, a novel hydrogen sulfide-releasing compound, protects against amyloid $\beta$-induced cell cytotoxicity. Neurochem Int. 2011;58(5):591-8.

28. Yu S, Lin S, Yu Y, Chien M, Su K, Lin C, et al. Isochaihulactone protects PC12 cell against $\mathrm{H} 2 \mathrm{O} 2$ induced oxidative stress and exerts the potent anti-aging effects in D-galactose aging mouse model. Acta Pharmacol Sin. 2010;31(12):1532-40.

29. Mehri S, Abnous K, Mousavi SH, Shariaty VM, Hosseinzadeh H. Neuroprotective effect of crocin on acrylamide-induced cytotoxicity in PC12 cells. Cell Mol Neurobiol. 2012;32(2):227-35.

30. Hosseinzadeh H, Shamsaie F, Mehri S. Antioxidant activity of aqueous and ethanolic extracts of Crocus sativus L. stigma and its bioactive constituents, crocin and safranal. Pharmacog Mag. 2009;5(20):419-24.

31. Dimri GP, Lee X, Basile G, Acosta M, Scott G, Roskelley 
C, et al. A biomarker that identifies senescent human cells in culture and in aging skin in vivo. Proceedings of the National Academy of Sciences. 1995;92(20):9363-7.

32. Song YS, Lee BY, Hwang ES. Dinstinct ROS and biochemical profiles in cells undergoing DNA damage-induced senescence and apoptosis. Mech Ageing Dev. 2005;126(5):580-90.

33. Liochev SI. Reactive oxygen species and the free radical theory of aging. Free Radic Biol Med. 2013;60:1-4.

34. Hosseinzadeh H, Sadeghnia HR, Ziaee T, Danaee A. Protective effect of aqueous saffron extract (Crocus sativus L.) and crocin, its active constituent, on renal ischemia-reperfusion- induced oxidative damage in rats. J Pharm Pharm Sci. 2005;8(3):387-93.

35. Hosseinzadeh H, Modaghegh MH, Saffari Z. Crocus sativus L.(Saffron) extract and its active constituents (crocin and safranal) on ischemia-reperfusion in rat skeletal muscle. Evid Based Complement Alternat Med. 2009;6(3):343-350.

36. Mousavi SH, Tayarani NZ, Parsaee H. Protective effect of saffron extract and crocin on reactive oxygen species-mediated high glucose-induced toxicity in PC12 cells. Cell Mol Neurobiol. 2010;30(2):185-191.

37. Chen L, Qi Y, Yang X. Neuroprotective effects of crocin against oxidative stress induced by ischemia/ reperfusion injury in rat retina. Ophthalmic Res. 2015;54(3):157-68.

38. Haider S, Liaquat L, Shahzad S, Sadir S, Madiha S, Batool Z, et al. A high dose of short term exogenous D-galactose administration in young male rats produces symptoms simulating the natural aging process. Life Sci. 2015;124:110-9.

39. Kuhla A, Ludwig SC, Kuhla B, Münch G, Vollmar B. Advanced glycation end products are mitogenic signals and trigger cell cycle reentry of neurons in Alzheimer's disease brain. Neurobiol Aging. 2015;36(2):753-61.

40. Pertyńska-Marczewska M, Kiriakidis S, Wait R, Beech J, Feldmann M, Paleolog E.M. Advanced glycation end products upregulate angiogenic and pro-inflammatory cytokine production in human monocyte/macrophages. Cytokine. 2004;28(1):35-47.

41. Tha KK, Okuma Y, Miyazaki H, Murayama T, Uehara $\mathrm{T}$, Hatakeyama R, et al. Changes in expressions of proinflammatory cytokines IL-1 $\beta$, TNF- $\alpha$ and IL- 6 in the brain of senescence accelerated mouse (SAM) P8. Brain res. 2000;885(1):25-31. 